This item was submitted to Loughborough's Research Repository by the author.

Items in Figshare are protected by copyright, with all rights reserved, unless otherwise indicated.

\title{
Design approach for the integration of services in buildings
}

PLEASE CITE THE PUBLISHED VERSION

http://dx.doi.org/10.1177/0143624412442510

PUBLISHER

SAGE (@) The Chartered Institution of Building Services Engineers)

\section{VERSION}

SMUR (Submitted Manuscript Under Review)

\section{LICENCE}

CC BY-NC-ND 4.0

\section{REPOSITORY RECORD}

Fouchal, Farid, Tarek M. Hassan, and Dennis L. Loveday. 2019. "Design Approach for the Integration of Services in Buildings". figshare. https://hdl.handle.net/2134/15241. 
This item was submitted to Loughborough's Institutional Repository (https://dspace.lboro.ac.uk/) by the author and is made available under the following Creative Commons Licence conditions.

\section{creative
commons}

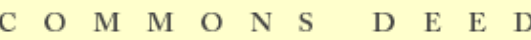

Attribution-NonCommercial-NoDerivs 2.5

You are free:

- to copy, distribute, display, and perform the work

Under the following conditions:

Attribution. You must attribute the work in the manner specified b the author or licensor.

Noncommercial. You may not use this work for commercial purposes.

No Derivative Works. You may not alter, transform, or build upon this work.

- For any reuse or distribution, you must make clear to others the license terms of this work.

- Any of these conditions can be waived if you get permission from the copyright holder.

Your fair use and other rights are in no way affected by the above.

This is a human-readable summary of the Leqal Code (the full license).

\section{Disclaimer 만}

For the full text of this licence, please go to: http://creativecommons.org/licenses/by-nc-nd/2.5/ 


\title{
Design Approach for the Integration of Services in Buildings
}

\author{
Dr. F. Fouchal ${ }^{1, *}$, Prof. T.M. Hassan ${ }^{2}$, Prof. D. L.Loveday ${ }^{3}$ \\ ${ }^{1,2,3}$ School of Civil and Building Engineering, Loughborough University, Loughborough, \\ Leicestershire, LE11 3TU, UK \\ F.Fouchal@1boro.ac.uk; T.Hassan@lboro.ac.uk; D.L.Loveday@lboro.ac.uk;
}

\begin{abstract}
This paper describes a novel methodology to group building services (BSs) into a single trunking system at minimal proximal distances between them. The study focused on solving the geometrical complexity encountered in conventional arrangements of BSs, while taking into account thermophysical and electromagnetic interactions between services together with building regulations. The potential solution for delivery and distribution of BSs in any number of directions is an 'onion layers' type of design, using novel mathematical manipulations based on manifolds of spherical and cylindrical geometries joined using Bezier surfaces. Computer Aided Design iterations were undertaken for channelling six BSs into a single unit including water, air, electricity and data. It consists of concentric cylindrical-spherical shells superimposed at few millimetres gaps (channels) for which physical prototypes were produced.
\end{abstract}

\section{Practical application}

Successfully integrating BSs such as water, air, electricity and data into a single trunking delivery system would offer an important advancement in reducing services installation cost, maintenance and the running cost of a building. Current design tools and techniques do not offer any solution for such integration; hence the current development of a multi services trunking system. Subject to satisfactory compliance with health and safety requirements, plus maintenance issues, the system is proposed for embedding into building construction walls, panels or for placement into a confined space as a first step toward next generation BS. It is foreseen that many industries and business will be involved in the early stage of this development.

Keywords: Building Services, Integration, Computer Aided Design, Additive Layer Manufacturing, Manifolds.

\section{Introduction}

According to many reports the building services (BSs) industry in the UK is worth about $2 \%$ of GDP with BSs systems being essential for the effective and efficient operations of buildings. BS routinely accounts for over $50 \%$ of the capital costs of new buildings and up to $70 \%$ of life-cycle costs ${ }^{1}$. They are central to the functional performance of buildings and to the necessary conditions for health, well-being, safety and security. Although BSs did not see any core transformation in the way they are physically operated or put together they are becoming increasingly technologically complex, for which their design and installation requires the involvement of numerous professions and trades. Designers and contractors working on the same project are frequently employed by different companies. The coordination of these participants and subsystems is crucially important for the optimum performance, and the involvement of several trades over a series of 'Fixes' increases the risk of practical problems being encountered, as well as increased time and cost of construction. Integration of utilities installation into a single fix by a single trade would therefore offer many advantages. Integration is crucial and its importance is widely recognised in other

\footnotetext{
* Dr Farid Fouchal

Civil \& Building Engineering, Loughborough University, LE11 3TU, UK

Tel: +44 (0) 1509228741

Email: F.Fouchal@lboro.ac.uk
} 
sectors such as aerospace and defence sectors where it has led to a major shift in procurement procedures.

The work reported here supports the efforts by many researchers around the world ${ }^{2,3}$ toward the realisation of the FreeForm 'mega scale' construction challenge, where building components could be fabricated in-situ by processes directly from 3D digital data using Additive Layer Manufacturing (ALM) processes. One of the principal advantages of ALM is the ability to manufacture working assemblies and linkages straight off the machine, which will lead in the future to the production of panel type constructions with fully embedded integrated services on site or in a factory environment. With current conventional fabrication methods this aim was impossible, consequently an investigation was undertaken and a new approach was developed. This method is to enable design and production of a multi service trunking system (MSTS) that is based on nodes (spherical) and runs (elongated cylinders). A node is the position along the service pipe, cable or/and duct at which distribution in more than one direction is required by splitting into two or more pipes, cables or ducts. This concept is developed by taking into consideration current building regulations/standards for the following services: hot and cold water, ventilation, electricity supply and data cabling.

Moving from conventional methods of delivering and distributing services within a building to a novel design concept using complex geometry was a result of a mathematical conversion of a linear tubular scattered system of services to an integrated, harmonised and parameterised model based on concentric 3D surfaces as detailed in this paper. The delivery of these services to any location in the building is therefore through a designed shell type arrangement of the channels (such as the 'onion layers') which are concentric and superposed on each other, combining spherical and cylindrical geometries. This setup displays all the channels 'empty gaps' in a way that allows access to any inter-layer space (space between consecutive two surfaces which is in fact the channel) from any orientation penetrating any other layers. This obviously needs to respect the proximal rule by keeping an empty circumferential space around the penetrating channel and the layer being crossed. On the 'node', any number, $\mathrm{n}$, of deliveries and distribution of services in any, $\mathrm{m}$, directions could be made. On the 'runs', services are delivered using a geometrically matched set of concentric cylinders made to connect in a simple manner to the spherical nodes.

\section{Prior state-of-the-art}

A literature review was conducted to discover whether BSs were integrated in any manner prior to this research work.

Marsh $^{4}$ has reported that the Danish construction industrial transformation needed to focus on integrating BS technologies in the buildings of the future. Historically across many parts of the world $^{5}$ there has been a large growth in the extent and costs of BSs over the last 100 years due to changes in social and technological development ${ }^{6}$. This is because the perceptions of buildings are changing from static and passive constructions to dynamic and adaptable functional spaces. In this process, intelligent $\mathrm{BSs}^{7,8}$ are becoming the driving force in meeting users' changing functional requirements over time. Consequently, new strategic design principles can be developed to integrate and distribute the expanding range of BSs into buildings, so that changing user demands for new intelligent BSs technologies can be incorporated into the building design and procurement process. Also the largest productivity gains from industrialisation ${ }^{9,}{ }^{10}$ can be achieved by focusing on BSs because they represent both a growing proportion of total construction costs, and are the least industrialised part of the construction process. The whole-building integration principle, similar to the process used in the production of automobiles which is designed and manufactured to optimise car performance, can be extended to include more physical integration of the different parts of the building. 
The new way to make buildings can be achieved through a unified physical infrastructure, starting with how systems are physically connected to one another and how they drive the information that is going to enable them to communicate ${ }^{11}$. The national building survey by Amory Lovins concluded that: "A lack of integration in the design process has made buildings costlier to build, costlier to cool, and less comfortable than they should be". This situation remains true today, especially for HVAC systems that are being imposed on buildings rather than integrated into them ${ }^{12}$, 13. The current drive within the construction sector is towards leaner, better Modern Methods of Construction $^{14}$, which undoubtedly can be reinforced by serious uptake of physical integration at every level of the construction processes from design all the way through construction to usage. Bemtgen ${ }^{15}$ proposed a detailed approach to make a transition from conceptual integration to physical integration. This starts with innovative planning and architecture, and then is followed by choosing Low-E materials, innovative components, and taking advantage of the innovation in Building Management Systems (BMS) including monitoring to finally succeed in physical integration.

A good example of physical integration (PI) encountered in the construction sector is related to energy efficiency of the building. There is a revolution in large scale integration of renewable energy sources with other building structural components. One example is the integration of photovoltaics (PV) into building facades and roof structures which are expected to provide a significant contribution to electricity generation, as described by Bahaj and James ${ }^{16}$. In essence this method is a combination of the mature tiles industry, with state of the art plastic and photovoltaic technology as a good step toward physical and functional integration.

There have been various views on how integration of building structural and functional components could improve the construction cost, the running costs and improve the user comfort ${ }^{17}$. However, all this integration was limited to the control and the operational aspects, with very little development being carried out on physically integrating the parts and the components that form buildings in general. We have therefore engaged into the development of a possible solution for integrating BSs using CAD surface and solid modelling tools. The generated models will be partly produced by ALM technology and partly by conventional manufacturing methods aiming for a sustainable solution, reduction in energy wastage, gain in material used for production and reduction in labour cost at various levels (handling, installation and maintenance) as described in this paper. The aim of this research is therefore to address all the challenges of PI of building services into a single trunking system.

\section{Physics study and standards review}

Combining all BSs into a single trunking system could be possible if interactions remain within the limitations imposed by currently applied building standards; the analysis alternates interactions between the different services and determines the risks involved if these services are brought nearer to each other than is allowed by the existing proximity limits. The potential risks of the proximity between services should then be identified together with possible solutions to overcome them. The PI difficulties to be overcome are related to the current manufacturing methods in construction, then the design practices of architects, designers, and service engineers, as well as issues related to materials performance, safety and longevity. Some of the materials tested within the produced prototypes during this research work showed some degrees of limitation which required more effort, time and cost to address. However, there are already some promising new materials being developed using nanotechnology engineered compositions (such as nano-ceramic or nano-clay particles filled polymers) to be considered for the MSTS, but this is outside the scope of this paper.

In this study, the preliminary design integration was restricted to incorporate in one unit the following: Hot and cold water for which a new connection protocol will be required to ensure good sealing at the joints between corresponding walls of the concentric layers of the following section of 
runs or nodes; air conditioning; data; and electric mains for which a new dedicated physical interface will be required. All designs and calculations were undertaken for a case study which comprised a hypothetical open plan office designed for twenty people. The following adopted parameters were based on the currently applied standard regulations, of the United Kingdom. These include:

- Water Supply (Water Fittings) Regulations, their Schedules which are Statutory Instruments (1999 No. 1148 and No. 1506) ${ }^{18}$;

- The British Standards: BS6700, BS CR 1752 and BS EN 1505, BS 7671 and BS6231;

- Physical laws that included Bernoulli's theorem for flow-metering; D'Arcy fluid flow and Fourier's Law of heat conduction ${ }^{19,20}$;

- Potable water proximities were calculated under the standard BS6700, where we have found that a $21 \mathrm{~mm}$ ID pipe will satisfy the water requirements for the chosen case study;

- Calculations for ventilation under standard BS CR 1752 and BS EN 1505 suggested that a prescribed flow rate of $8 \mathrm{~L} / \mathrm{s} /$ occupant of fresh air which summed for 20 people can be carried by a duct of 436-483 mm ID when conventional flow rates are applied;

- For electric power under the standard BS 7671 and BS6231, $15 \mathrm{~kW}, 240$ volts single phase AC @ 60 Amps is needed to satisfy all personnel and equipment requirements of the open space plan;

- For data the category 8 (CAT8) cables which are 4 x 22/1 AWG will be adequate and will satisfy the needs for more digital applications in the future.

Using these standards and principles, calculations of the proximal distances for the case study were made. The corresponding dimensions and specifications were obtained using standard building services calculation methods, the results to retain are as follows: $21 \mathrm{~mm}$ ID pipe to satisfy the hot and cold water requirements, $8 \mathrm{~L} / \mathrm{s} /$ occupant of fresh air equal which needs a duct of 436-483 mm ID, $15 \mathrm{~kW}, 240$ volts single phase AC at 60 Amps for electricity requirements and category 8 (CAT8) cables for data. The proximal distances were based on achieving minimal energy loss or exchange between services and ensuring zero leakage of water especially toward electricity cables. These measures have to account for thermal insulation for which a geometrical positioning of the services (pipes, ducts and cables) is needed to allow a safe distance between electricity and water to maintain compliance with current building regulations. Obviously integration of all services into a single trunking will result in considerable challenges to address. The following sections will address the essential elements of this integration, which are: (1) respecting the proximal rules for safety, (2) respecting the proximal rules for optimal thermal insulation between hot and cold services, (3) distribution at nodal points without breaching the proximal rule and (4) joining and connectivity of the different components.

\section{Methodology}

The methodology undertaken to develop an integrated multi services trunking consist of:

(i) Analysis of the current building standards, to filter which regulation to account for in the new design

(ii) Conducting a physics study to understand the interactions (thermo-physical and electromagnetic) between services

(iii) Undertaking a mathematical development to allow geometrical integration of BSs into a single trunking and permitting distribution in all directions

(iv) Generation of CAD models, from which physical prototypes will be produced using ALM.

The key steps necessary to perform the described development begin by defining the interactions between the services and their interactions with the materials to be used to make the integrated trunking, taking into account the findings from the building regulations review. The next step is to conduct a physics study to calculate the permissible distances between the services once brought 
together in a bundle assembly to allow generation of 3D CAD models of the integrated trunking solution.

For the present design approach, the intended services to be transported by the new trunking system are considered Once integrated in concept, and the 3D CAD models are produced, an evaluation of the solution is carried out prior to production of physical prototypes which will undergo further laboratory studies in regard to their functionality. A variety of sensor components will also be embedded into the trunking for communication with building operating systems on functionality as well as for informing on user's activity. Each stage of the analytical process is described in the sections that follow.

\subsection{Initial attempts at an integrated building services solution}

Initial attempts at integrating all the six stated BSs using the findings from section 3 has resulted in several potential solutions for bringing together all the services pipes, cables and ducts into a bundle form under various arrangements. The approach was simple arrangements which comprise: a flat surface (see figure 1), the internal surface of a square or rectangular duct, or the internal surface of a cylindrical duct. As can be seen in figure 1-a, these arrangements were made within the proximity distances calculated. However, although the proposed solutions seemed interesting they struggled to satisfy the proximity rules when distribution at nodal points was required. In other words, there is not a solution which could allow the calculated proximal distance to be respected if the number of distributions needed in, $n$, directions is greater than two $(n>2)$ as can be seen from figure 1(b) with the exception of when pipes or ducts have to cross the living space of a building. Consequently, distribution in more than two directions at the nodal point has made these integration solutions impractical and unusable. Further research was then undertaken at a fundamental level to reach a solution that would be valid mathematically as regards respecting the proximal rules in all situations.

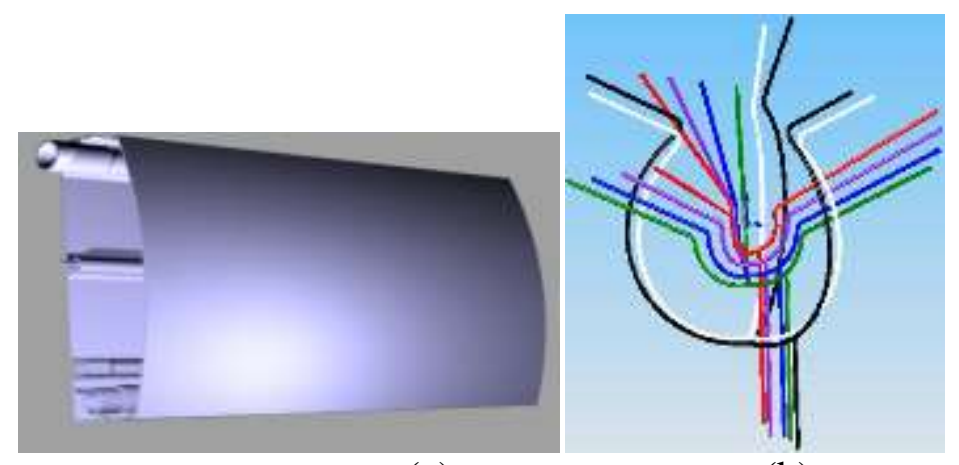

(a)

(b)

Figure 1 Initial solutions included 2D and 3D pipes distribution

There is a high risk of complications if the 2D/3D type of distribution shown in Figure $1 \mathrm{~b}$ is put into practice. Physical resistance to flow coupled with difficulties for linking of electrical cables to supply ring or radial circuits are among the limitations of such a design. Breaching of the proximity rule at distribution points is also a hurdle that this design is impractical and better to be abandoned at the design stage without undergoing any laboratory testing program. This limitation becomes more apparent at split or distribution points where pipes, ducts and cables have to be directed in multiple directions whilst still respecting the proximal rules.

However, analysis of this solution has led to understanding of the real problems to be tackled when trying to physically integrate building services into a single unit. Its presentation as part of this work is an essential step in analysing the transition from conventional ways of distribution of services to the MSTS approach by first solving the limitation of simply bundling normal pipes, ducts and cables in $2 \mathrm{~d}$ and $3 \mathrm{~d}$ fashion. 
It is possible to perform an automated 2D and 3D layout within the current practice of BSs based on the current design and installation methods. However, doing so will only add different geometrical changes to the way services are laid-out at the moment. The possible advantages of automation need to be evaluated in a separate study. For the purpose of this study, automated 2D and 3D layout will not facilitate the integration of BSs into a single unit; we need to search beyond 2D and 3D bundling of services.

\subsection{The Multi-Services Trunking System (MSTS) Concept}

The obstacle described in the previous section (4.1) has led to further investigations regarding the geometric arrangements for integrating the BSs into a single trunking.

Conventional methods of distributing services in buildings follow a set of different routes throughout the building (of pipes, ducts or cables) for services (such as hot and cold water, ventilation, electricity, data, and waste water plus gas). These routes extend from the main entry point as the services arrive at a building all the way to where they are needed. In current practices, generation of these paths depend on the preferences of the different contractors responsible for each service, who usually follow the less installation time and less complexity which results in unrecognisable pattern of the paths followed. The current work is aimed at investigating a transition from this conventional way of thinking to a more advanced method where all the services are integrated into a single set of routes. While these routes can be related by a mathematical function (for all the services) to keep them at a fixed distance from a single common trajectory (calculated in 3D space) while they distribute through the building. This means that this transition involves passage from the current distribution of each service following separate scattered 3D set of trajectories, to a single common 3D trajectory, which is in fact performing the integration of all the services into a single trunking.

The proposed concept consists of allocating new geometrical forms for the channels (pipes, ducts) by physically reshaping the external surfaces of the conventional type of tubing into pairs of concentric surfaces such that the space between them provides the channels for services. The common trajectory which was proposed earlier can be considered as an imaginary dimension that does not physically exist but encompasses the linkage of the concentric surfaces along a single path. The surfaces comprise a set of overlapping 3D concentric layers of spheres ('nodes') joined to the long cylinders ('runs'), such that within the node, services can be distributed in any number of directions. The node is designed to perform services distribution without breaching proximal rules; any given service is therefore allowed to cross other services layers under provision of a partly blocked peripheral area around it within all the crossed layers to maintain the proximity rule between services. This can be seen from Figure 4, which shows a distribution node.

The suggested transition requires complex mathematical manipulation which will take into consideration usage of minimum space occupation within the building and allow full geometrical integration of BSs by means of a new concept. This transition is twofold; first, we have defined the types of the 3D surfaces to be used (here they were boundaries of cylindrical cavities, which are trapped between layers that are concentric and extend along common axis/trajectory from the point of entrance into the building to the position in the building where the service is required), and then second, we have proposed a solution to link the corresponding surfaces together. The solution that was identified to potentially answer the question is based on coupled spherical and cylindrical shapes which are already overlapped into manifolds and joined using harmonised Bezier surfaces ${ }^{21}$ The integrated services manifold (trunking) contains as many overlapping (superimposed) concentric spaces as needed to deliver an "infinite" number of services and distribute them without breaching the calculated proximity rules as opposed to the initial solutions (given in section 4.1). 
For this purpose a mathematical development was sought. It was based on designing a manifold by coupling spherical and cylindrical geometries using Bezier surfaces, all arranged around the common central path forming a set of concentric shells similarly to the 4D thinking ${ }^{22}$. It has allowed transition from the impossible distribution of services in many (greater than two) directions when simply bundled together in a 3D curved fashion, to a design which allows flexible distribution in any number of directions. This solution is also intended for further embedding of future BS services into building construction walls, panels or for placement into a confined space within a building and is a first step toward next generation BS.

The influence of the interactions between the services has been studied in two main respects, namely electromagnetic and thermo-physical aspects as follows:

(i) Study of how the electromagnetic (EM) fields generated by electric currents in the mains cable influence the signals within the data cable (these are mainly conversion of the EM into an interfering signal in the form of noise).

Proximal rules between electric and data cables are based on the UK technical recommendation (EN 50174-2; while Coaxial cabling for distribution of television and sound signals is covered in EN 50083) which states that: " The minimum segregation distance between power cables and IT balanced cables for cable lengths of up to $90 \mathrm{~m}$ is $75 \mathrm{~mm}$. This minimum distance applies to $230 \mathrm{~V}$ ac, $20 \mathrm{Amp}, 50 / 60 \mathrm{~Hz}$, single phase circuits, with a maximum of ten such power cables. A three phase $415 \mathrm{~V}$ ac circuit would account for three of the former power cables. Outlet boxes that share power and data circuits must keep $6 \mathrm{~mm}$ segregation. $130 \mathrm{~mm}$ separation from fluorescent lights is still required.

To comply with this and to remedy the possible interferences, conventional approaches were adopted; the data cable is designed in a way to stop the build-up of the interference generated, namely self-attenuation or annealing is achieved by the spiral shape design of each data cable as shown in figure 5 . The second part of the solution was designed as a metallic shield which is physically integrated into the inter-shell spacings immediately around where the data cable is located. It is made of a low temperature melting alloy which is introduced all the way around the spiral data cable. Combination of the spiral geometry and the $2 \mathrm{~mm}$ thick metallic shield might be regarded as an over engineered solution to protect data signals from any sort of interferences.

(ii) A study to understand the thermo-physical interactions has also been conducted. For example heat could be transferred from hot water/air to cold water/air between the concentric channels of the MSTS as both are kept within the same unit. Proximal distances were calculated on the basis of how much of this thermal energy is transferred /lost.

In the MSTS whenever there is a temperature gradient, heat is transferred by conduction from hot to cold water through the solid separation (Resin \& Silicon) and out from the opposite surface to the surrounding medium (water) by convection. To illustrate how this thermal energy transfer occurs we are going to simply analyse the geometry of the MSTS and produce the rate of heat transfer from hot to cold fluid. For this we will need the convection heat transfer coefficient and the combined/relative conductivity of the wall (made of three layers). The question to be answered: how much heat is picked up by the cooled fluid and what is its temperature change? Then how does this relate to the MSTS design and its particularity?

To illustrate the MSTS geometry in a simplified way, let's consider a couple of concentric cylindrical tubes where hot water flows on one side of the separation wall (internal pipe) and cold water flows on the other side. An illustration of temperature distribution due to heat transfer from one side of the separation wall to the outer layer on the other side of the wall is as shown in figure 2: 


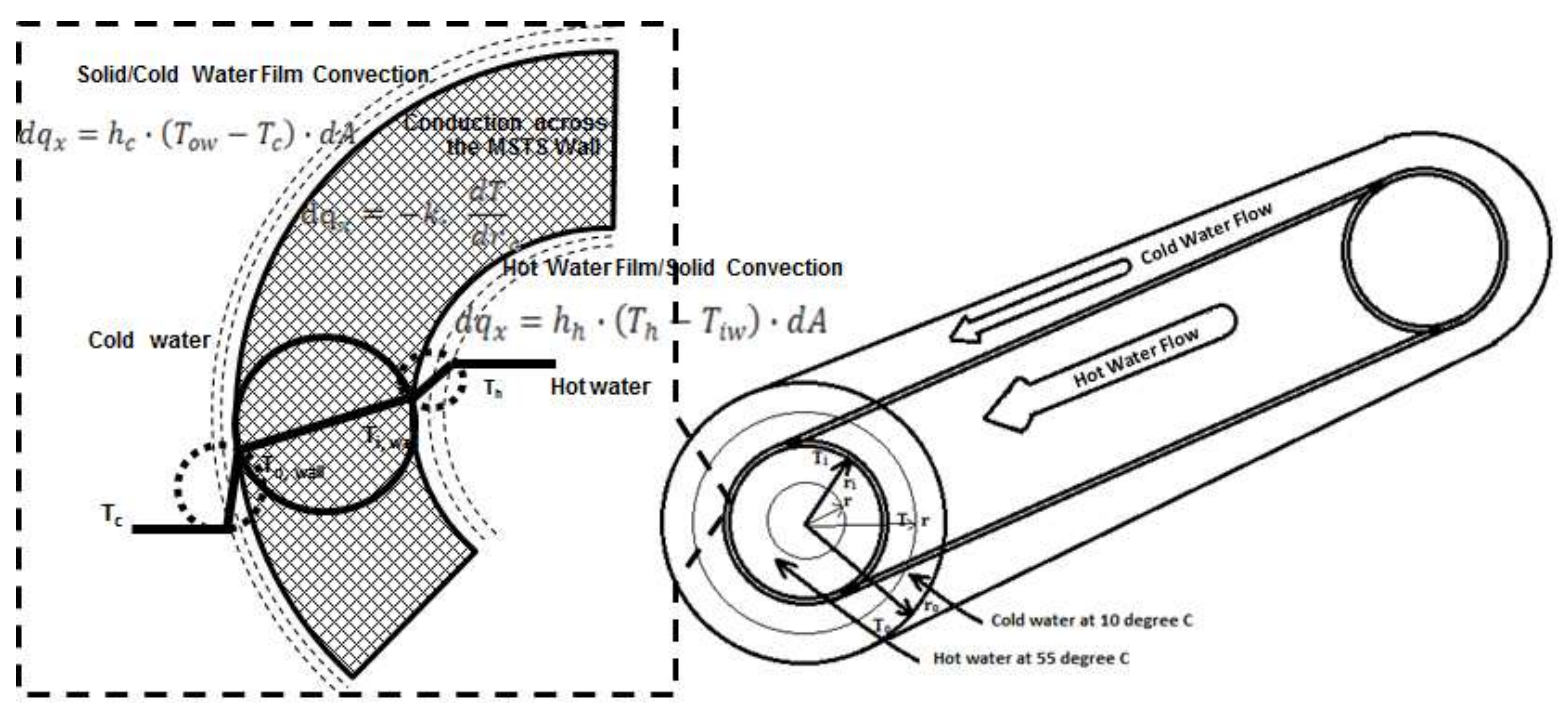

Figure 2 Temperature distributions from hot to cold water through the MSTS solid wall

If the MSTS is simply represented by a tube as shown in Figure 2, then $T_{o \text {, wall }}$, is the temperature at the outside surface of the wall while $T_{i \text {, wall }}\left({ }^{0} \mathrm{C}\right)$, is the temperature at the inside surface of the separation wall while $\mathrm{L}$, is the length of the cylinder, and $k$ is the thermal conductivity of the wall, which is a combination of thermal conductivities of two materials, that of the $4 \mathrm{~mm}$ thick silicon layer, $K_{\text {silicon }}$, which is sandwiched between a pair of $2 \mathrm{~mm}$ thick layers of epoxy/acrylic resin, which are, $K_{\text {resin }}$. The three equations of the rate of conduction-heat transfer for the three layers are written as follows:

$$
\dot{Q}_{1}=\frac{2 \pi k_{\text {resin }} L\left(T_{i, \text { wall }}-T_{1}\right)}{\operatorname{Ln}\left(\frac{r_{1}}{r_{i, \text { wall }}}\right)}, \dot{Q}_{2}=\frac{2 \pi k_{\text {silicon }} L\left(T_{1}-T_{2}\right)}{\operatorname{Ln}\left(\frac{r_{2}}{r_{1}}\right)}, \dot{Q}_{3}=\frac{2 \pi k_{\text {resin }} L\left(T_{2}-T_{o, \text { wall }}\right)}{\operatorname{Ln}\left(\frac{r_{o, \text { wall }}}{r_{2}}\right)}
$$

Where, $Q_{i}$, is the heat flow in input or loss $(\mathrm{J} / \mathrm{s}=\mathrm{W})$. Assuming there is a perfect surface contact between layers; thermal energy is transferred through the three layers by conduction and passed directly from one to another, as the temperature of both layers at the contact surface is the same.In the case under study the heat transfer area increases as the radius increases from inside toward outside of the cylindrical wall, but due to the low ratio of wall thickness to cylinder radius the changes were not included in the calculations.

A good estimate for the heat transfer coefficient, $h,\left(W /\left(m^{2} K\right)\right)$, is often the most difficult part of forced (mechanically pumped circulation) convection heat transfer calculations. The process for estimating the heat transfer coefficient for a particular forced convection application is often through a correlation for Nusselt number $(\mathrm{Nu})$ in terms of Reynolds number $(\mathrm{Re})$ and Prandtl number (Pr), which are dimensionless numbers as defined below, along with the definitions of some of the parameters that appear in them.

$$
N u=\frac{h D}{k_{\text {water }}}, \quad \quad R e=\frac{D V \rho}{\mu}, \quad \operatorname{Pr}=\frac{\mu C_{p}}{k_{\text {water }}}
$$

$D=$ difference in pipe diameter $(m), V=$ water velocity $(\mathrm{m} / \mathrm{s}), \rho=$ density of water $\left(K g / \mathrm{m}^{2}\right), \mu=$ water viscosity.

Nusselt Number Correlations for Turbulent Flow Inside a PipeThe Dittus Boelter equation ${ }^{23}$, which has: $\mathrm{Nu}_{\mathrm{o}}=0.023 \mathrm{Re}^{0.8} \mathrm{Pr}^{0.4}$, for 'heating' (temperature of wall $>$ temperature of fluid), and $\mathrm{Nu}_{\mathrm{o}}=$ $0.026 \mathrm{Re}^{0.8} \mathrm{Pr}^{0.3}$, for 'cooling' (temperature of wall $<$ temperature of fluid). Subject to: $0.7<\mathrm{Pr}<$ $120 ; 10,000<\operatorname{Re}<160,000 ; L / D>10(L / D>50$.

$$
N u_{o}=\frac{\left(\frac{f}{8}\right)(R e-1000) \operatorname{Pr}}{1+12.7\left(\frac{f}{8}\right)^{0.5}\left(\operatorname{Pr}^{\frac{2}{3}}-1\right)}\left[1+\left(\frac{D}{L}\right)^{\frac{2}{3}}\right]
$$

Where: $f=(0.790 \ln R e-1.64)^{-2}$, for: $\operatorname{Pr}>0.7, \operatorname{Re}>2300$

As a result the convective heat transfer coefficient for water is estimated to be within the range: 
$h_{\text {water }}=50-10.000\left(\mathrm{~W} / \mathrm{m}^{2} \mathrm{C}\right)$

The equations for the rate of convection-heat transfer between the hot water and the surface of the solid separation and between the solid separation and the cold water are as given bellow:

$$
\begin{gathered}
Q_{\text {hot water region }}=h \cdot A \cdot\left(T_{\text {hot water }}-T i_{o, \text { wall }}\right), \text { and } \\
Q_{\text {cold water region }}=h \cdot A \cdot\left(T_{o, \text { wall }}-T_{\text {cold waterc }}\right),
\end{gathered}
$$

Where, $A$ is the heat transfer surface area $\left(\mathrm{m}^{2}\right)$. Now if we consider hot water to flow over a cylindrical surface of $L=1 \mathrm{~m}$ long by $W=0.2 \mathrm{~m}$ circumference with a bulk temperature of $55^{\circ} \mathrm{C}$ and the temperature of the cold water is considered to be around $10^{\circ} \mathrm{C}$, whereas convective heat transfer coefficient is $2000 \mathrm{~W} / \mathrm{m} 2^{\circ} \mathrm{C}$ and the temperature of the solid wall to change from $37^{\circ} \mathrm{C}$ to $28^{\circ} \mathrm{C}$ across the whole thickness $(8 \mathrm{~mm})$ and stabilizes at this rate after 20 minutes of water circulation. Then the thermal energy transferred to the solid wall is equal to: $7200 \mathrm{Watt}$, and the thermal energy transferred from the wall to the cold water is 7200 Watt.

If the flow through the pipes is $0.5 \mathrm{l} / \mathrm{s}$, and both hot and cold water are flowing in the same direction then heat transfer rate will become constant over time as the same amount of heat that is lost to cold water is continuously replaced through the feed of new hot water from heated water tank.

Consequently the cold water will exit the MSTS with 7200 joules every 3600 seconds, which is 2 $\mathrm{J} / \mathrm{s}$. The specific heat coefficient of water is $c=4.18(\mathrm{~J} / \mathrm{g} \mathrm{C}), m$, is the mass of the water leaving the MSTS every second. As a result the temperature of the cold water when it leaves the MSTS is 13.44 ${ }^{0} \mathrm{C}$, as can be seen in the following:

$$
\begin{gathered}
\text { Using: } \mathrm{Q}=\mathrm{m} \cdot \mathrm{c} \cdot r^{2}\left(\mathrm{~T}_{\mathrm{f}}-\mathrm{T}_{\mathrm{i}}\right) \\
T_{f}=\frac{Q}{m \cdot c}+T_{i}=\frac{7200}{500 \cdot 4.18}+10=13.44 C^{0}
\end{gathered}
$$

As a result and depending on $T, h$ and the thickness $D$, the heat transferred from hot to cold fluids through the solid wall may vary. Thus, increasing the $U$ value through usage of low k materials together with increasing wall thickness will have a major effect on reducing heat losses within the MSTS. There is also a potential for heat recovery if a third fluid is introduced in a channel between the hot and cold water channel.

A functional MSTS was designed on the basis of the newly developed mathematical solution (manifold "nodes and runs" joined by Bezier surfaces). The MSTS designs were carried out in CAD using Rhino software, as can be seen in figure 5. They represent a succession of concentric shells (sphere and cylinder which are linked) containing internal series of empty concentric gaps as conduits for services and are ready to be filled with thermal insulating material such as silicon sealant or electromagnetic shielding material such as low melting alloys to be an integral part of the solution. The empty gaps will serve as channels for services in a similar manner to pipes and ducts that are conventionally used for plumbing and ventilation. The node is particularly innovative in that it guarantees distribution of services in all directions and in any number of directions, while runs are designed to cross long distances to link the distribution nodes.

The arrangements of the services requirement as calculated for the 20 people open plan office in the case study is also given in figure 6. 


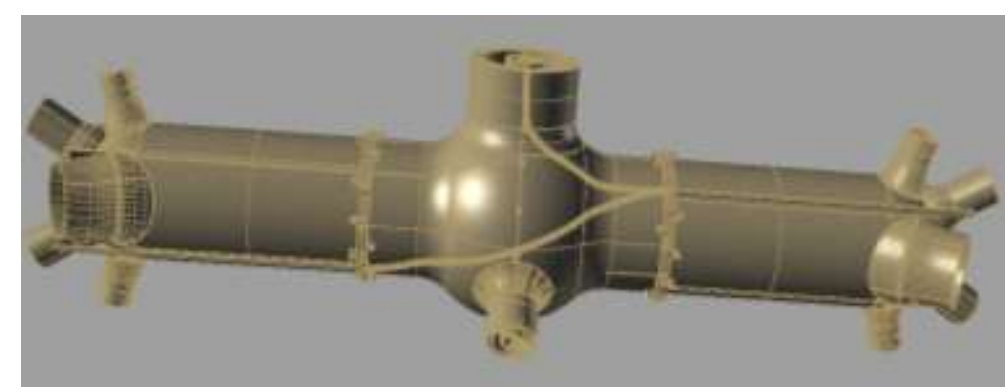

Figure 5 Optimised novel solutions - MSTS

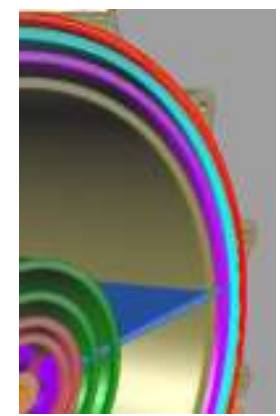

Outer shell/O-ring groove

Inner Low Melting Alloy

Inner water shell

Inner Silicon/outer ventilation

Inner ventilation

Inner silicon

Inner water

Inner Low Melting Alloy

Data twisted cable

Electric cables

Figure 6 Coloured illustration of an optimised MSTS for 20 people open plan office case study.

The final CAD complex geometries shown in figure 5 could be physically produced by a combination of two manufacturing technologies; one could be conventional to produce the runs directly by simple extrusion of any complex pattern while the most geometrically complex part that is the node (which is shown in figure 7) could be produced by an advanced manufacturing technique such as Additive Layer Manufacturing (ALM).

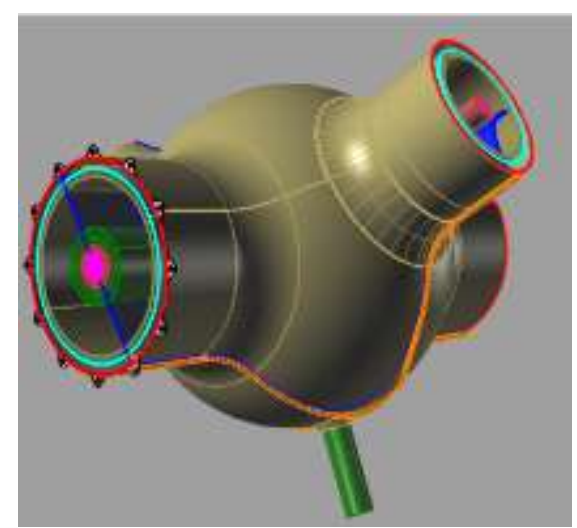

Figure 7 Distribution "Node" for the optimised novel solution - MSTS

In regard to the interface with other systems in a building, the MSTS is designed to operate in combination with the conventional services such as those existing for distribution around the building. The MSTS will be used to deliver services as far as possible to units of the building that require them (e.g. flats or rooms). The interfaces to conventional distribution circuits (piping, ducting and cables) or when services leave or enter a T-junction are made either at the node or at terminations of runs which will be specifically made and designed in CAD, then produced as part of the MSTS ready to connect to conventional systems in practice. Initial attempts have been made and used in the current work, as can be seen in figure 8 . 


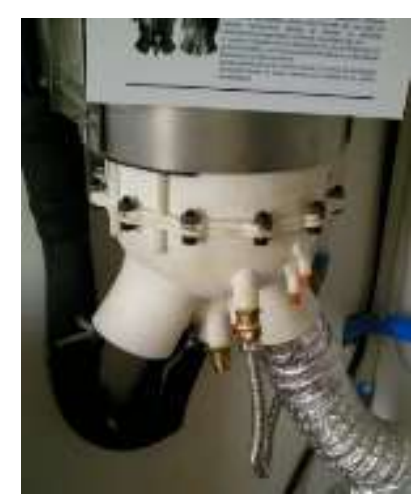

Figure 8 Interface of MSTS to BSs conventional system.

\section{Physical MSTS prototype}

Once the prototype MSTS is designed and produced, its ability to deliver water, air, electricity and data can then be investigated in the laboratory. This new concept for services delivery will be compared with standard methods (e.g. saving space, trades, time, energy etc). A number of physical prototypes were produced for experimental purposes and for design improvement and refinement. Assessment of material requirements in terms of manufacturability and usability was performed and several existing materials for ALM processes were tested. These materials were polymers, specifically designed for Stereolithography systems (which is an ALM process). They were Accura 60 plastic and the WaterShed XC11122. A number of thermal insulation materials were also tested as they may improve the overall thermal insulation of the MSTS walls and the physical integrity of the trunking when fluids (including the high viscosity silicon sealants) are forced into the narrow gaps between the concentric shells of the MSTS. These were Cerafix Translucent Silicone Sealant and SylGuard Silicon 184. Furthermore, a low melting alloy material was also filled into the space around the spiral channels for data; this was the MCP 47 which has a low melting point of $47{ }^{\circ} \mathrm{C}$.

For the manufacturing of the geometrically complex node, ALM is taken as a solution. At its core lies the principle that processes may be numerically controlled to make things 'directly' without tooling or casting. Knowing that indirect and offsite methods for construction are the only way of realising highly complex geometries and structure at the moment. As a result of ALM an important change could be possible to the way we make our habitats. These will be highly optimised with capability to induce environmental control by evolving construction methods which utilise geometric forms. Freeform Construction technology is making the new generation of homes become a reality ${ }^{2}$. The ALM technology was therefore adopted and used to produce the MSTS prototypes. In figure 9 one can see some of the prototypes which were produced and were used for the experimental program, results of which will be the subject of a future publication.

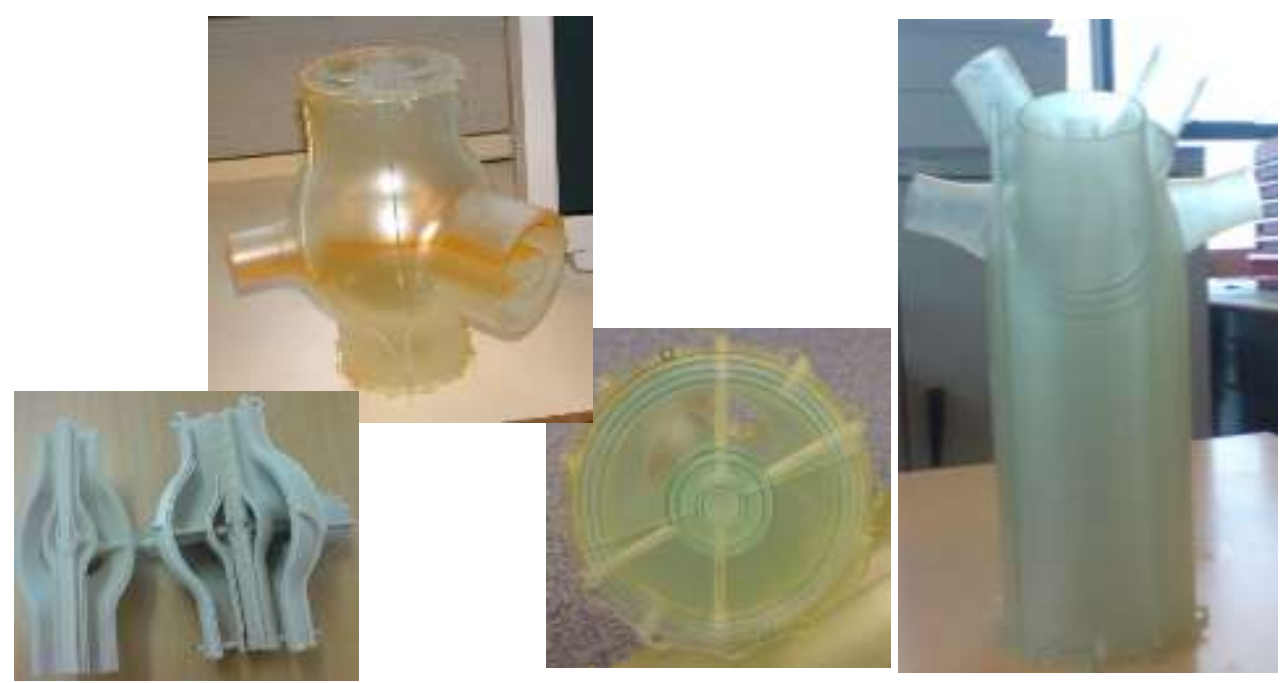


Figure 9 Physical prototypes of Node and run as produced by Additive Layer Manufacturing technology

\section{Maintenance, repair and health and safety}

These issues require full and thorough investigation prior to any practical usage of the innovative concept suggested in this paper. However, an initial approach is suggested as follows. An isolation principle was adopted and designed into the MSTS inter channel spacings. It uses a thick silicon film that sandwiches any channel allocated for water or air, and it also uses a low melting alloy shield around where a data cable is placed. The set of thick $(2-4 \mathrm{~mm})$ isolation layers are designed for incorporation into their designated spacings once the MSTS runs and nodes are pre-joined (such as by push fit or similar) all the way throughout the whole building. By doing so, the introduced low viscosity fluids are mechanically pumped into the MSTS and are vacuum aspirated from the opposite end of the trunking to allow filling up by the material into the whole designated cavity (spacing). The silicon-based mix is selected to solidify once trapped into the closed spacings as it contains a resin-based compound for curing after some time (about 24 hours). In each of the concentric layers, the isolation layer is continuous throughout all the joined runs and nodes. This should not only strengthen the trunking, but also ensure sealing at joint locations and thereby produce a fluid and gas leak-free system aimed at ensuring compliance with health and safety regulations. Although the above approach should be effective in principle, this method poses a number of problems as regard to maintenance. In the situation of failure of any given channel within the trunking, the whole section will have to be replaced. This is the only solution to date, and this may close down the whole trunking during failure and repair time. As it stands, customised ALM (Additive Layer Manufacturing) technology is the only way to enable production of the MSTS node or run quickly (in a day or less). However, in-built extra channels for safety or to aid maintenance could be incorporated into the original MSTS for temporarily redirecting the services from the failed channels and thus allow time for the facility management team to plan and organise the installation of a replacement part(s).

\section{Initial reaction of facility managers}

Facility management (FM) experts (two senior FMs in one visit, and an enterprise adviser with strong FM background in another visit in addition to a number of academics) have been invited to assess and comments on the MSTS as an alternative for the current BSs systems. Their comments together with their feedback covered the design, installation and maintenance aspects. The discussions were analysed and condensed, highlighting their reactions, concerns and some of their advice as given in the following.

They have asked about how the MSTS would be provided into the current stock of buildings, where all houses are different with different needs or is it only designed for repetitive type of houses. How adaptable is the MSTS, as in conventional ways if we get it wrong, we simply cut the pipe away and re-do-it again. Not always services can be centralised, generally they are distributed in different directions, where, in the MSTS these are integrated in one unit and splits at the node, and how realistic is the flexibility of the node. In terms of installation, how the joining and the insulation between the services could be achieved. In the unfortunate situation of having a problem within the MSTS, all services have to be stopped to carry out any repair. In BS installation the biggest problem is when things do not work at the end, then comes testing to commission and so on. And the apparent complexity of this system may increase the commonly known problems of BSs. Besides when you have a service you obviously need access to dumpers, motors, how this would be performed with the MSTS. What are the interactions between the materials used to build the MSTS and with the different services? There are going to be problems (such as deposited material builds up), have you carried out a risk analysis, if the MSTS fails then; water, gas, electricity all together 
in one single unit do present some serious or deadly combinations? And not to be ignored are the unpredictable variables. In practice we come across a range of problems: leaks coming up from the way services are put together, pipes do come off, solders give up or are badly applied, water quality varies, and/or Legionella Bacterium related problems.

The possibilities with this system are endless, you can snake it around the difficult parts of a building (move things around buildings freely) you can also put it in constrained spaces. You can also imagine the architectural expression of this. As it is designed for production by ALM it works both ends of the scale (modular) or for very specialised end. It can get you out of problems when you are restricted with space or in emergency situation.

Some of the responses to the concerns highlighted above are provided in the following. With ALM if you can design an object then you can print it (physically build it) at no extra cost for geometrical complexity. The MSTS will be built in accordance to information on the building usage and the 3D geometric data, allowing for virtual visualisation and testing before any production happens to minimise the risk of getting wrong in the first place. However, it is estimated that about $27 \%$ of the produced parts will be recycled if an error does occur (which is based on conventional scrap rate with particular factors of the MSTS such as unusual appearance). In the face of surface deposition and corrosion, as a long term solution, nano-engineered self-cleaning surface technologies are the way forward for the MSTS. Furthermore, the nodes (and even the runs) can be over designed (25\% extra size) to allow for certain amount of alterations when needed. Spaces between pairs of concentric surfaces are the channels for services and nodes are spheres of larger diameter than the runs, where channels present wider cross sectional areas for the fluids to flow through and allow for branching off from any internal layer. On the other hand, the technique which is designed and tested for introducing the insulation material and the low melting alloy shielding material produces a set of concentric single insulation and shielding layers which are connected all the way through the MSTS tree forming a fluid and energy sealed envelope. In addressing one of the major concerns which is when we get into serious trouble with the MSTS while in operation, the only solution so far is to replace the whole faulty section. Usage of wireless monitoring sensors for help fast fault localisation to simplify and minimise the repair response time and the building management system sends warning signal to the facility manager and a signal to an ALM machine to build the replacement part.

As a conclusion our approach in this work is very much a concept with practical advantages, some investigations were performed, but there is still a long way to go, which we recognise in this paper.

\section{Conclusion and discussion}

In Summary this paper has presented an innovative concept of combining multiple services within a single trunking system. The mathematics of manifolds and Bezier surfaces have been used to propose a 'nodes and runs' approach for routing the services and trunking through a building, whilst preserving required spacing between services.

This investigation suggests that successfully integrating (BS) services into a single trunking delivery system would offer an important advancement in reducing services installation cost, maintenance and the running cost of a building. Important saving on energy and time of manufacturing, assembly and maintenance can also be claimed together with near zero material wastage during the production process which is possible through ALM. Improve safety in this sector by its pluggable components and system configuration and sensor assisted assembly. Investigation is still continuing looking potentially at the use of new materials being developed using nanotechnology engineered compositions. These will be considered for further studies and developments of more prototypes of this integrated BSs single components. This is very much a 
concept with practical advantages, and some investigations done, but there is still a long way to go, and which we recognise and plan for.

Maintenance remains the biggest problem so far and the complexity of this system may increase the commonly known problems of BSs. As it stands the only realistic solution if maintenance or repair is requested is by changing the whole faulty section by a new one. Usage of embedded monitoring and sensing technologies will facilitate fault localisation and reduction of the reaction time. In case of fault occurrence the Building Management System would send a request for production (by ALM) and replacement of the failed part. Furthermore, extra channels within the MSTS could be incorporated in the original MSTS for temporarily redirecting (when possible) the services from the failed channels and allow time for repair with minimal obstruction to users.

There are also a number of other concerns, such as: the di-electricity of the material used for the MSTS and its electromagnetic interactions with the services, the design for fail-safe in the situation of leakage and diffusion of gases and liquids within the trunking. Difficulties in choosing a single material for conveying different services (as current ALM processes use single materials) as another type of problems which need further investigations. Furthermore, a list of some identified obstacles include: Setting up the standards and regulations for the MSTS; Acceptance by the market, industry and user; Selection of the materials in terms of properties, manufacturability, cost and for incorporation into living environment; Absence of robust procedure for ensuring continuation of other service operation at time of failure or undertaking the repairs.

\section{Future work}

Based on the MSTS, design and production of a building to custom fit any need can be fully automated. In the Building information modelling (BIM), usage of MSTS will enrich the computational capabilities and will permit generation of the whole MSTS tree in accordance to data on users' needs everywhere in a building. As an addition to BIM, it will enable calculation of the best pathway for the MSTS tree throughout the building, but most importantly it will inform the production services to manufacture the MSTS section or components for best installation and maintenance program.

Rigorous testing (as outlined above) in the laboratory is now required to fully evaluate the practical feasibility of the proposed concept. Such testing is essential prior to any installation in real buildings on the fronts of health and safety. The new system also remains to be tested in regard to its ease and speed of installation as well as real cost in comparison with conventional systems. Tests may involve assessing performances as well as advantages in contrast with the conventional services delivery systems.

\section{Acknowledgements}

The authors would like to thank all members of the research group for their support during this work at both the research and experimentation stage. The corresponding project (I3CON Industrialised, integrated, intelligent construction) has been partially funded by the European Commission (EC) under its Sixth Framework Programme (FP6). The authors do also gratefully acknowledge the support of the EC and the contributions of all the partners in the project.

\section{References}

[1] Clements-Croome D. "Systems Integration for Building Services Project" as viewed on June 2010, available at: http://www.icrc-reading.org/projects/projectdetails.asp?ProjectID=14.

[2] Soar R, Fouchal F. Construction Processes for the Digital 'Trinity'. 1st International Conference on Industrialised, Integrated and Intelligent Construction, UK. 14-16 May 2008; 295-214. 
[3] Khoshnevis B. Automated Construction by Contour Crafting - Related Robotics and Information Technologies. Journal of Automation in Construction - Special Issue: The best of ISARC 2002; 13(1): 5-19.

[4] Marsh R. Future Directions for Building Services Technologies in Denmark. 1st International Conference on Industrialised, Integrated, Intelligent Construction, UK. 2008; 99-107.

[5] Banham R. Architecture of the Well-tempered Environment, Second edition. London. The Architectural Press; 1984.

[6] Bauman Z. Liquid Modernity. Cambridge: Polity Press; 2000.

[7] Clements-Croome D. Intelligent Buildings: Design, Management and Operation. London:

Thomas Telford; 2004.

[8] Duffy F, et al. New Environments for Working. London: Spon Press; 1998.

[9] Dicks M. Innovative M\&E Data Sheets (ACT 5/2002). Bracknell: Building Services Research and Information Association; 2002.

[10] Mawdsley M, et al. Effects of modular building services distribution on construction sequence, time and cost. In: CIBSE National Conference, Regents College, London, Chartered Institution of Building Services Engineers; 2001.

[11] Yasin R. Systems integration the key to green buildings, experts say. Dec. 10, 2009,

Government Computer News; 2009. Document available at:

http://gcn.com/articles/2009/12/10/green-it-smarter-buildings.aspx

[12] Amory L, et al. Least-cost climatic stabilisation. Annual review of energy and environment; 1992; 16: 433-531.

[13] Amory L B. Profitability bating global warming. Japanese-American conference on global warming, Atlanta. June 3-4 1991.

[14] Lovell H. Modern Methods of House Building. London: Parliamentary Office of Science and Technology; 2003.

[15] Bemtgen J M. The European Energy Approach, for Sustainable Building and cities, Unit Innovation and Technology development in Energy. Versailles, FR, 21 November 2006.

[16] Bahaj A S, James P A B. Photovoltaic roof tiles: design and integration in buildings,

Sustainable Building. BEPAC + EPSRC Conference, University of Southampton, UK, 5/6

February 1997.

[17] Vaidya P, et al. Integrated Cost-estimation Methodology to Support High Performance

Building Design. Energy Efficiency. 2009; 2: 69-85.

[18] The Water Supply (Water Fittings) Regulations, 1999. ISBN 011082552 7. Document available at:http://www.opsi.gov.uk/si/si1999/19991148.htm.

[19] Liu S. On Fourier's Law of Heat Conduction. Continuum Mechanics and Thermodynamics. 1990; 2: 301-305.

[20] Liu I S. Method of Lagrange multipliers for exploitation of the entropy principle. Archive for Rational Mechanics and Analysis. 1972; 46-131.

[21] Wilson M J, Martin R R. Mathematics of surfaces. 10th IMA international conference, Leeds, UK. 2005; 263-264.

[22] John D Norton. What is a four dimensional space like? Available at:

http://www.pitt.edu/ jdnorton/teaching/HPS_0410/chapters/four_dimensions/index.html

[23] Petukhov, B.S., "Heat transfer and friction in turbulent pipe flow with variable physical properties," Adv. Heat Transfer 6, 503-565. 1970. 